\author{
A. Tamadon*, D. J. Pons, K. Chakradhar, J. Kamboj, D. Clucas \\ University of Canterbury, Department of Mechanical Engineering, Christchurch 8041, \\ New Zealand
}

*abbas.tamadon@pg.canterbury.ac.nz

\title{
3D-PRINTED TOOL SHOULDER DESIGN FOR THE ANALOGUE MODELLING OF BOBBIN FRICTION STIR WELD JOINT QUALITY
}

\begin{abstract}
A variety of tool shoulder designs comprising three families i.e. blade, spiral and circular shaped scrolls, were produced to improve the material flow and restrictions to avoid the tunnel void. The bobbin tools were manufactured by 3D printing additive manufacturing technology using solid filament. The butt weld joint was produced by each tool using plasticine as the workpiece material. The apparent surface features and bi-colour cross-sections provided a physical flow comparison among the shoulder designs. For the bobbin friction stir welding (BFSW), the tool shoulder with a three-spiral design produced the most stability with the best combination of the flow patterns on surface and cross-sections. The circular family tools showed a suitable intermixing on the surface pattern, while the blade scrolls showed better flow features within the cross-sections. The flow-driven effect of the shoulder features of the bobbin-tool design (inscribed grooves) was replicated by the 3D-printed tools and the analogue modelling of the weld samples. Similar flow patterns were achieved by dissimilar aluminium-copper weld, validating the accuracy of the analogue plasticine for the flow visualization of the bobbin friction stir welding.
\end{abstract}

Keywords: bobbin friction stir welding; analogue modelling; material flow; tunnel void

\section{INTRODUCTION}

Friction stir welding (FSW) is a solid joining process, invented by Wayne Thomas and patented by The Welding Institute (TWI) in 1991 [1]. Bobbin friction stir welding (BFSW) is a self-reacting variant of the conventional FSW, whereby a weld is formed by the plastic deformation directed by the tool through two pieces of substrate material [2-4]. The weld is produced by plastic mixing of the material rather than melting as in the traditional fusion welding processes [5], resulting in better physical and mechanical properties within the weld structure [6-8]. Moreover, the required heat-input in dual-rotation shoulders in the BFSW 
process is less than other tool designs. This welding process does not consume external material [9] and does not emit harmful fumes [10], therefore it is an environmentally friendly [11]. It is a relatively novel method of joining, and it has been successfully applied to several manufacturing industries such as shipbuilding, automotive and aerospace industries [1215].The bobbin friction tool uses zero down force and eliminates the use of bottom supporting plate compared to the conventional friction stir welding [16]. This innovative tool design facilitates automation of the welding process. The balanced forces also facilitates design of the welding machine easy. Initially this welding was applied for aluminium due to its low melting point and suitable formability. The further development in this bobbin technique helped to weld magnesium and steel of certain thickness. The limitations lie in the defects and material flows [17]. The entry and exit defect due to the rotation of tool is problematic and can only be eliminated by inconvenient drilled holes and tools capable of disassembly. The key quality failing of the weld structure is the emergence of void defects formed at the middle of the weld breadth between the advancing side (AS) and the retreating side (RS). The literature shows a relationship between the occurrence of the void defect and interruption of material flow regimes [18-20], where the deposited stirred mass forms band patterns at the joining bond layer [21]. During the refilling process at the trailing edge of the advancing tool, the insufficient material flow from retreating side to advancing side at the pin affected zone (PAZ) of the weld causes a shortage of downward material transportation in the shoulder affected zone (SAZ) [22]. These are the primary and secondary reasons for occurrence of the tunnel void.

Research continues to explore for better tool designs for development of the weld properties and elimination of the void defects. During the stirring, the tool features influence the quality of the weld by the interaction between the mass flow layers at the plasticity region. The shoulder tool profile has a significant effect on the quality of the weld [23]. This has been correlated with the shoulder-driven flow, induced through the stirring zone of the weld [24]. Previous investigations also report a direct relationship between the shoulder-driven mass flow and the absence or occurrence of defects in weld regions [23, 24]. The scrolled shoulder has an advantage of minimising flash, due to the improved engagement between the shoulder and the workpiece [25], where the plasticised mass flows are entrapped within the surface grooved features. As the tool transports surface material from the leading edge toward the retreating side of the tool, the scroll moves material toward the tool centre [26].

The purpose of this study was to understand the effect of shoulder geometry on the quality of the welded joint.

\section{EXPERIMENTAL}

Different families of shoulder profiles were used during the experiments. Analogue modelling using plasticine was used as the method to visualise the flow. In other areas plasticine has been used for analysis of the plastic deformation processes [27-29]. Use of a soft material like plasticine rather than aluminium or some other metal allowed the tools to be manufactured with 3D printing. This allowed a variety of shapes to be checked, including some that would otherwise be difficult to machine. This has not been attempted before in the literature, except an unrelated attempt to manufacture metal tools this way [30].

Two different coloured plasticine slabs were used as the weld workpiece. Different colours of plasticine manufactured by New Clay Products - United Kingdom, were rolled to a uniform thickness of approximately $10 \mathrm{~mm}$ by a cylinder-shaped roller and using glycerine as the lubricant, to dimensions of $100 \mathrm{~mm}$ (length) $\mathrm{x} 30 \mathrm{~mm}$ (width) x $10 \mathrm{~mm}$ (thickness). Each piece was cut as given in Figure 1, to produce butt joint weld components. The blocks were 
heated at a temperature of $60^{\circ} \mathrm{C}$ for a period of two hours. The heated blocks of plasticine cooled down gradually to $-4^{\circ} \mathrm{C}$ as the working temperature. Glycerine liquid was used as lubricant between the tool and substrate slabs, to reduce smearing.

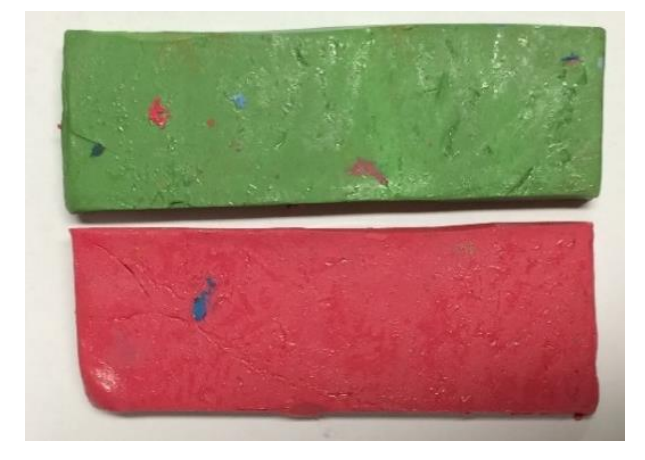

Fig. 1. Plasticine slabs employed as the butt-weld samples

The bobbin tool consisted of a top shoulder, a bottom shoulder and fixed pin in the centre. The cylindrical homogenous threaded pin was used to provide uniform welding material flow and mixing zone. The top and bottom shoulders had the same features and profiles, in pairs. Different families of shoulder designs (spiral, blade, circular) were produced. An overall schematic of the tool design and assembly is shown in Figure 2.

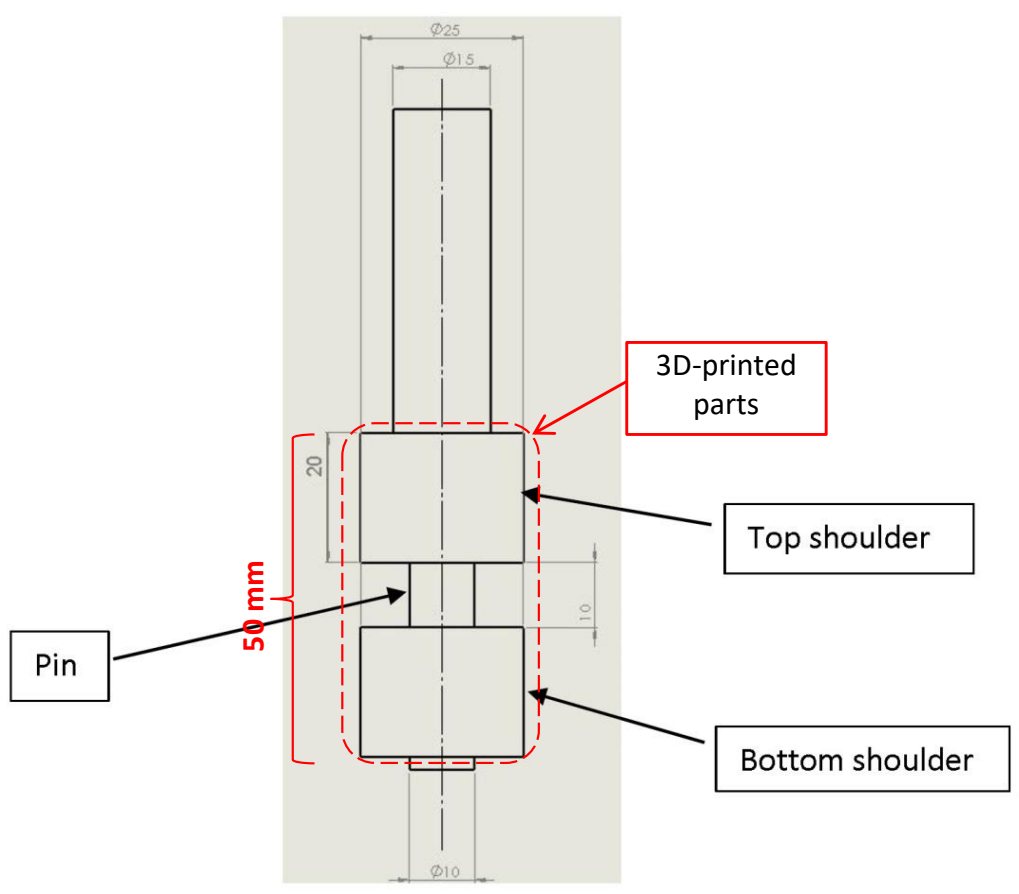

Fig. 2. Fixed-gap bobbin tool design

Various scrolled profiles (spiral, blade and circular grooves) were produced on the shoulder surfaces. The experiments were run using a manual milling machine. The feed and speed process parameters were $50 \mathrm{~mm} / \mathrm{min}$ and $50 \mathrm{rpm}$ respectively. Shoulders were $25 \mathrm{~mm}$ in diameter and $1.5 \mathrm{~mm}$ deep, with the pin having diameter and height of $10 \mathrm{~mm}$. The shoulders were designed to flow the material inwards by the clockwise rotation of the tool, see Figure 3. 

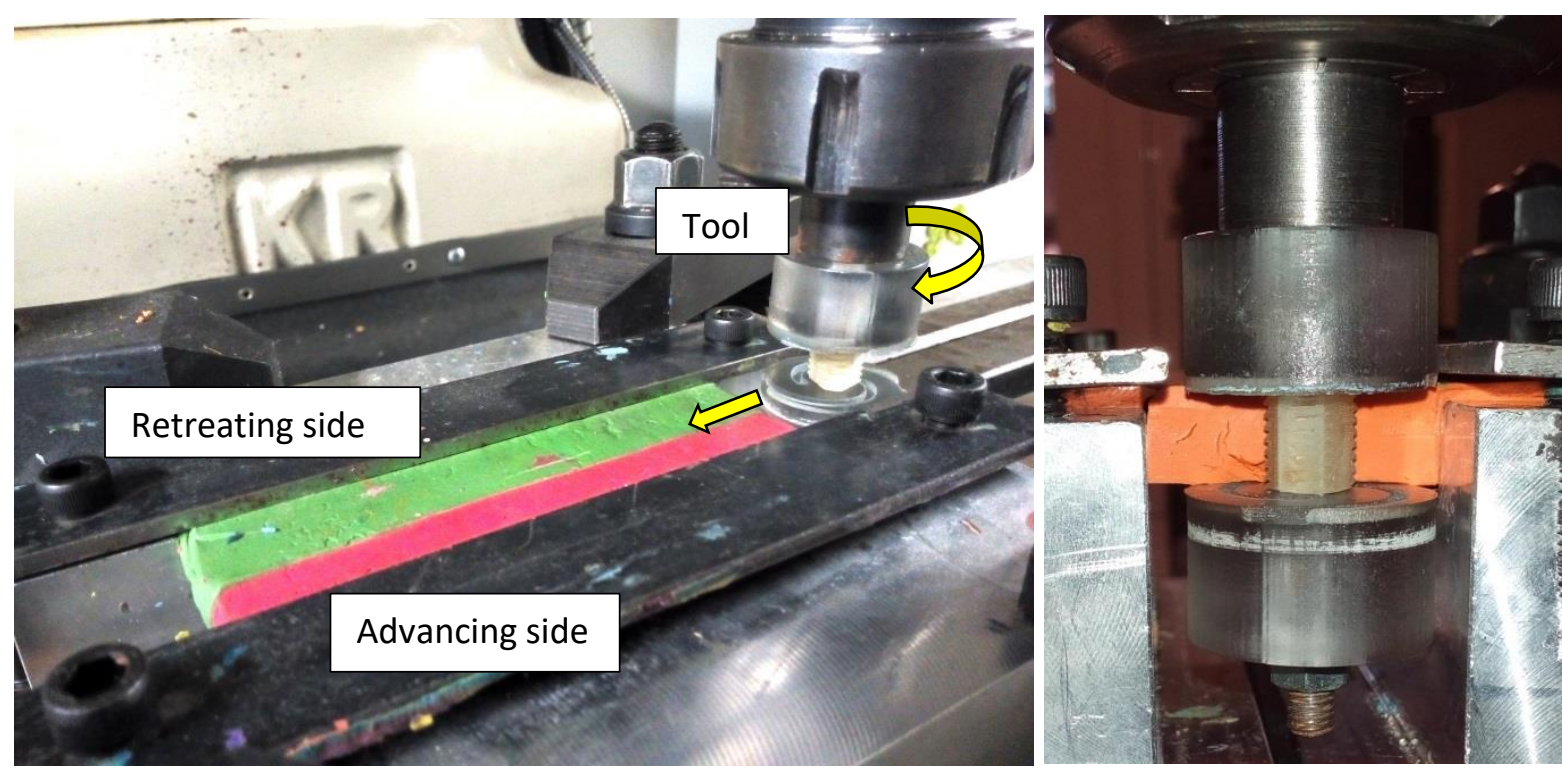

Fig. 3. Schematic of bobbin friction stir welding process; 3D-printed tool in interaction with plasticine substrate

The tools used in these experiments were manufactured by additive manufacturing process, using Stratasys VeroClearTM plastic in a Stratasys Connex 3D Printer (Eden Prairie, MN, USA) without post-processing. The shoulders were manufactured in transparent plastic to allow material flow visibility during the welding process. The pin tool was also made of the same plastic material. The surface roughness of the 3D printed parts was below $0.2 \mathrm{~mm}$. The tool assembly was made in such a way to easily interchange the shoulders for the experiments.

The shoulder families are shown in Figure 4. Some of the shoulder designs were mixtures of the families. All tools were designed to rotate in the clockwise direction. The operational speeds were just sufficient to establish a joining layer for the plasticine analogue samples to model the bobbin friction stir welding. The material flow and working principle is shown in Figure 5.
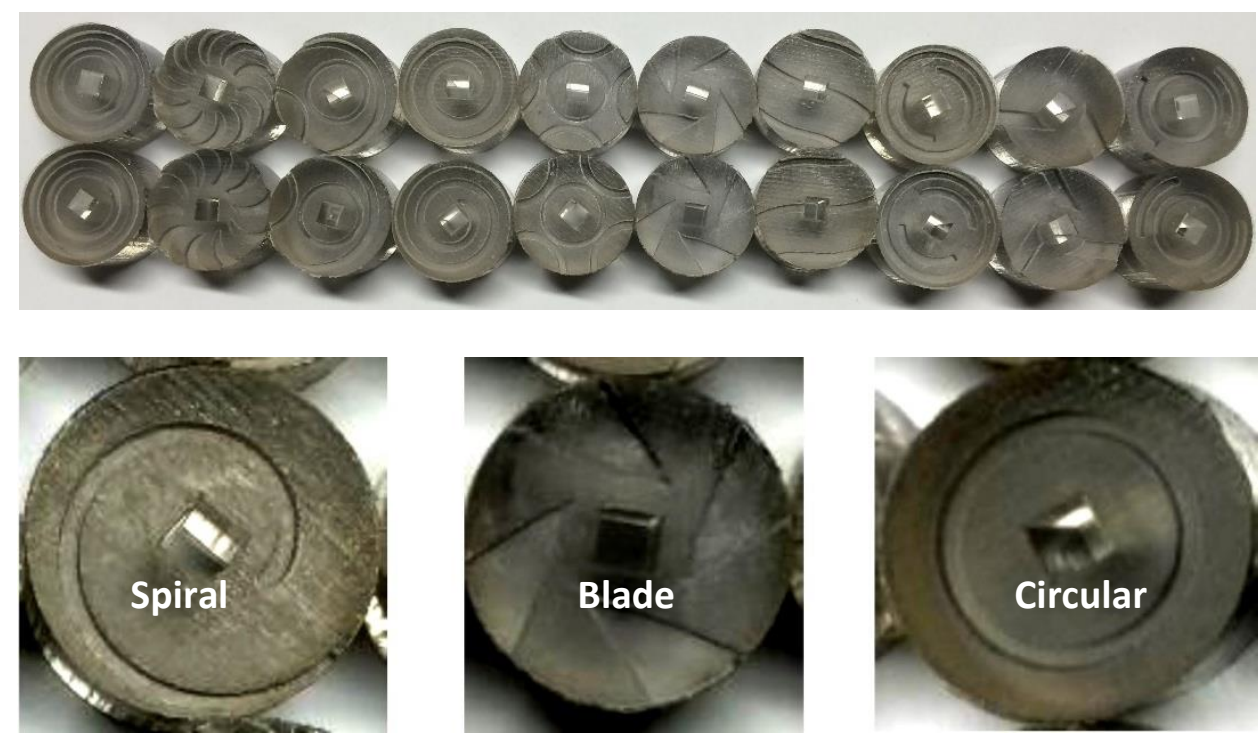

Fig. 4. 3D-printed scrolled shoulder designs used for the analogue modelling of the BFSW process 

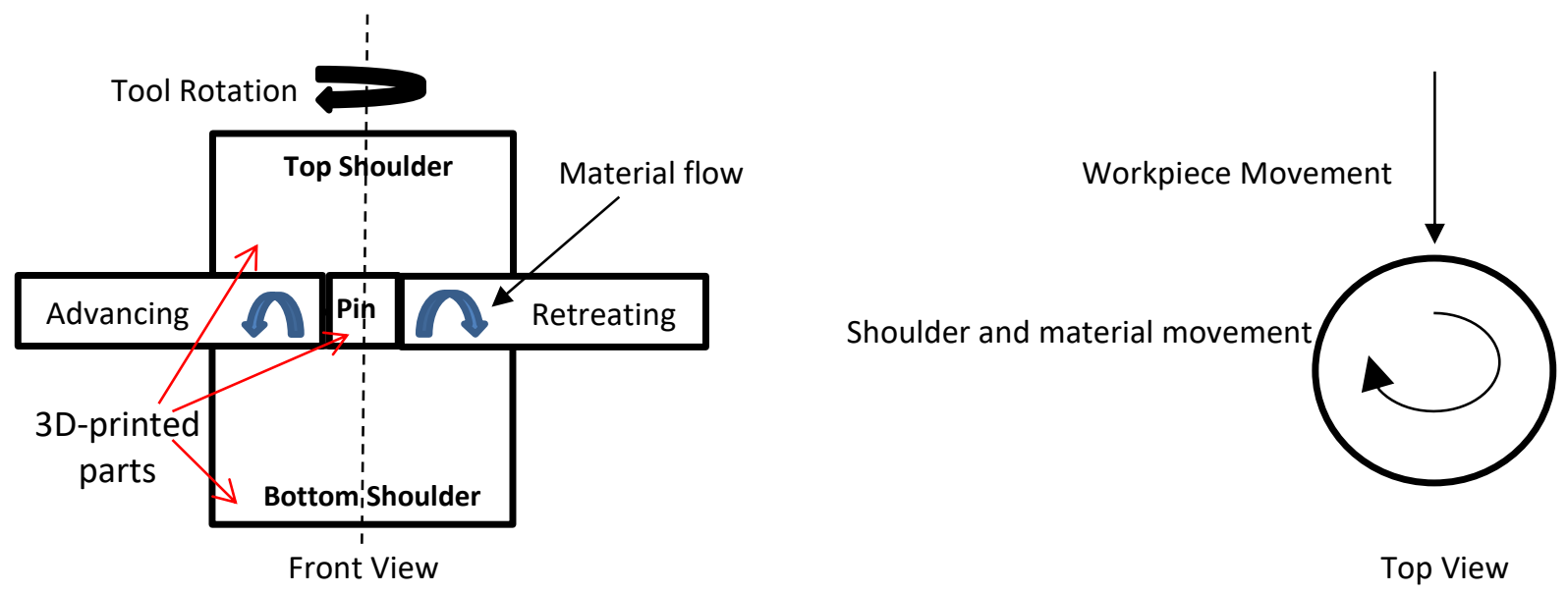

Fig. 5. The principle of the stirring action and mass flow as the tool-substrate interaction in BFSW process

After completion of all tests, the surface quality of the weld was examined through visual inspection and photographed. After the surface evaluation, the plasticine samples were cross sectioned and studied for the tunnel void as shown in Figure 6.
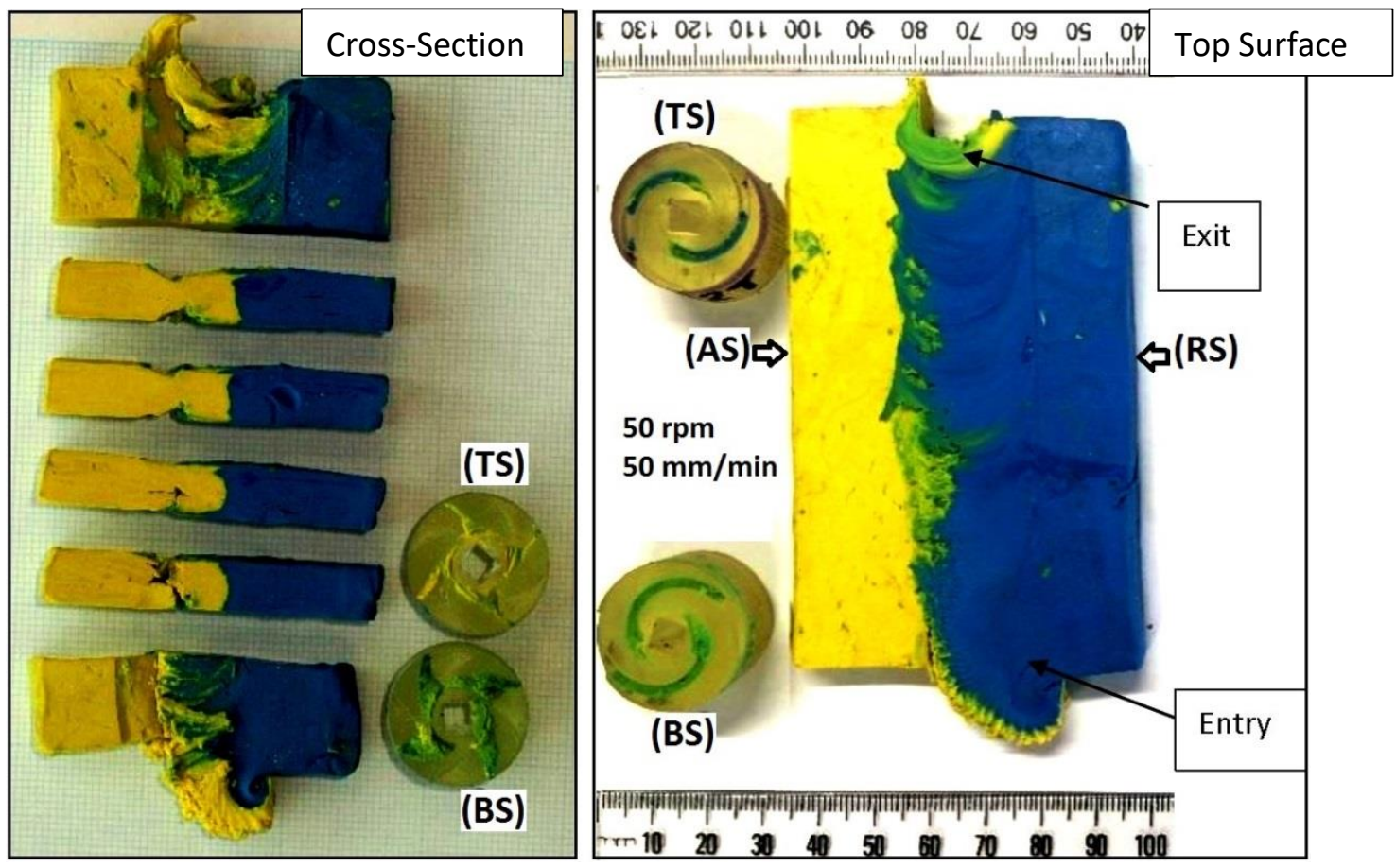

Fig. 6. Analogue plasticine weld samples; surface flow features and cross-sectional flow patterns (AS: advancing side, RS: retreating side, TS: top shoulder, BS: bottom shoulder) 


\section{RESULTS}

Besides tunnel void, there existed entry and exit defects in the welded workpieces as shown in Figure 6. These defects were almost identical in all the weld samples. As the position of shoulders with respect to the workpiece was advancing (tool was fixed and feed given to the workpiece), when the shoulder approached near the entry area, the mass flow transported from the advancing to the retreating section. Since there was no backing material at initial start, the excess material was ejected on the retreating side. This formed a spray-tail and an associated entry-zone defect. Similar flow conditions at the exit zone occurred where there was lack of material at front of the shoulder. This forms a key-hole shape as the exitzone defect.

\section{Surface Flow Patterns}

The surface quality of each test had been visualised and then compared to each other among the shoulder families and on basis of the shoulder profiles. The mix of bi-coloured slabs made it possible to estimate the depth impact of the shoulders, and show the extent to which material was transferred from one side to the other.

\section{(1) Wider the cutting profile, degraded quality of surface produced}

It is evident from Figure 7 that the wide cutting profiles resulted in poor-quality surfaces in comparison to the narrow profiles. The figure shows a blade feature with four cutting profiles.

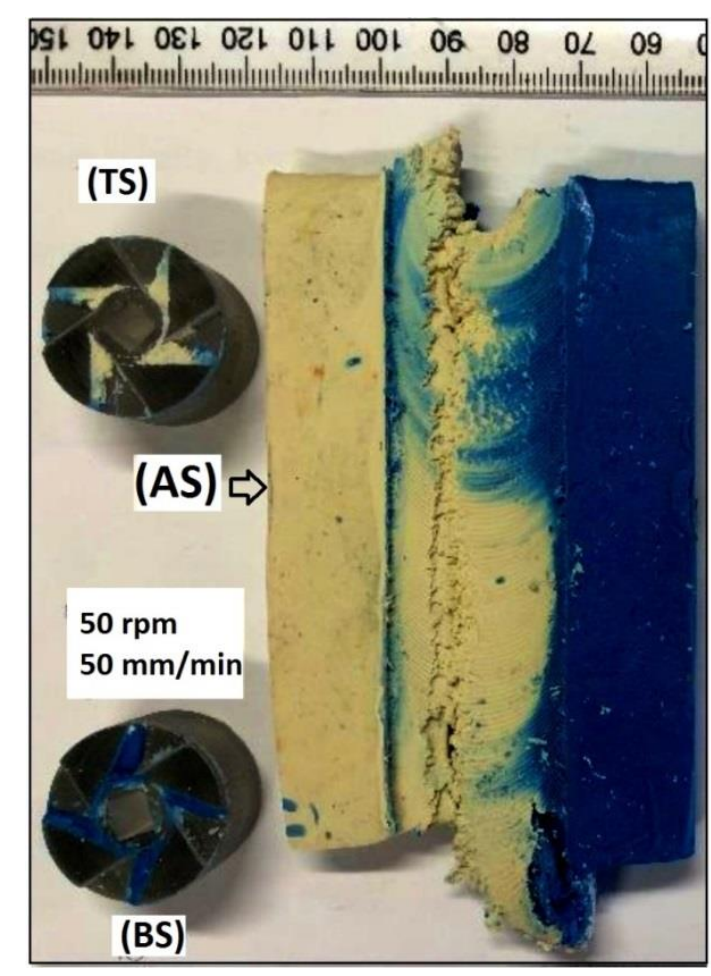

A

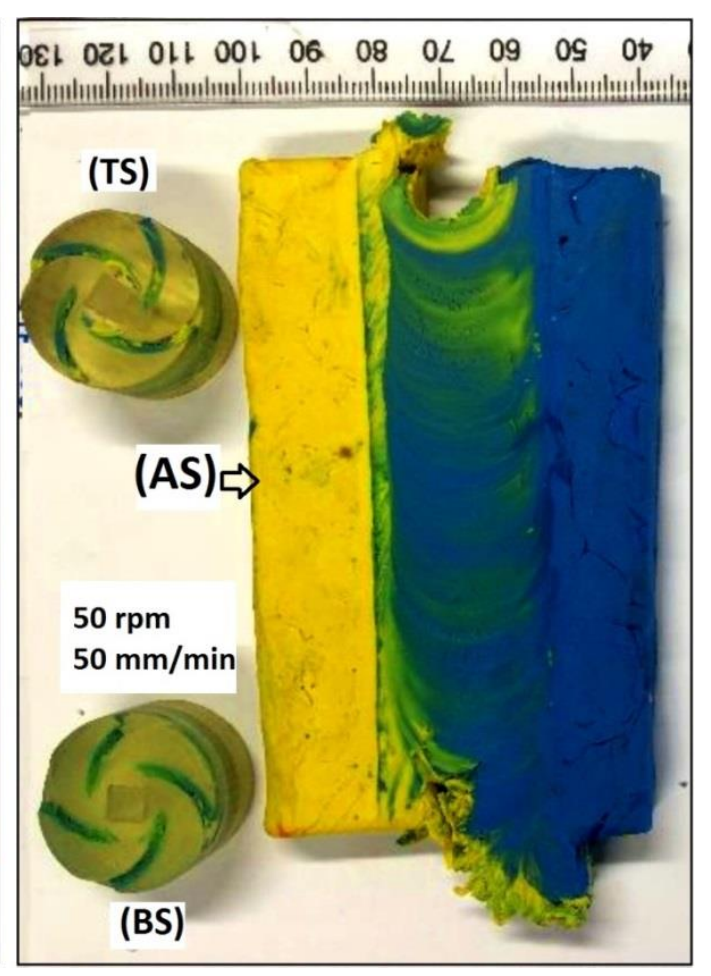

B

Fig. 7. Flow features from top surface (AS: advancing side, RS: retreating side, TS: top shoulder, BS: bottom shoulder) 


\section{(2) Larger the number of the cutting profiles, more flow complexity at the surfaces}

Generally, the more aggressive the shoulder geometry, the worse the weld quality. The comparison of double and multi spiral shoulders is shown in Figure 8.

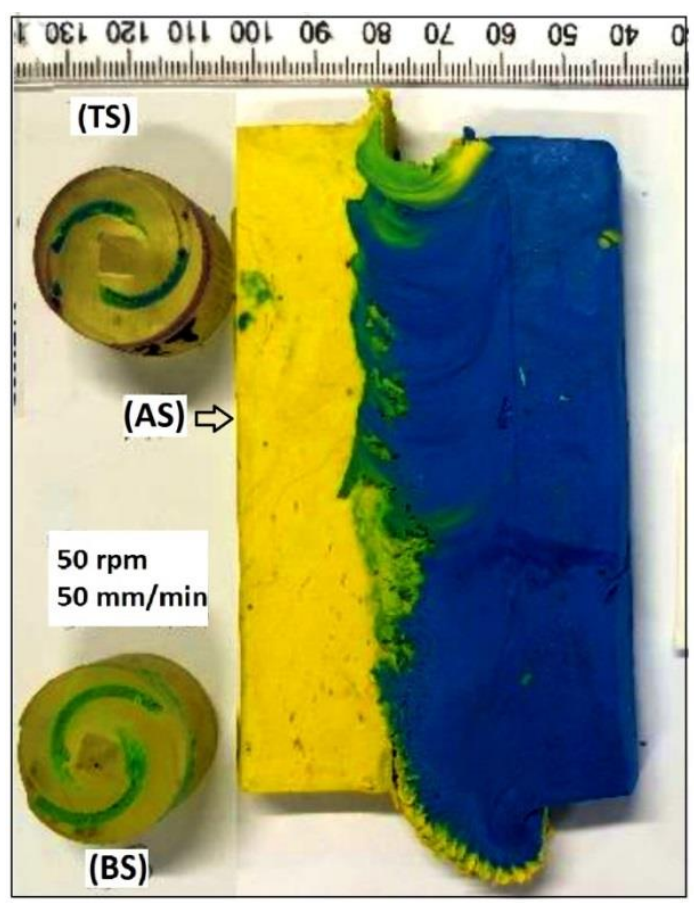

Double Spiral

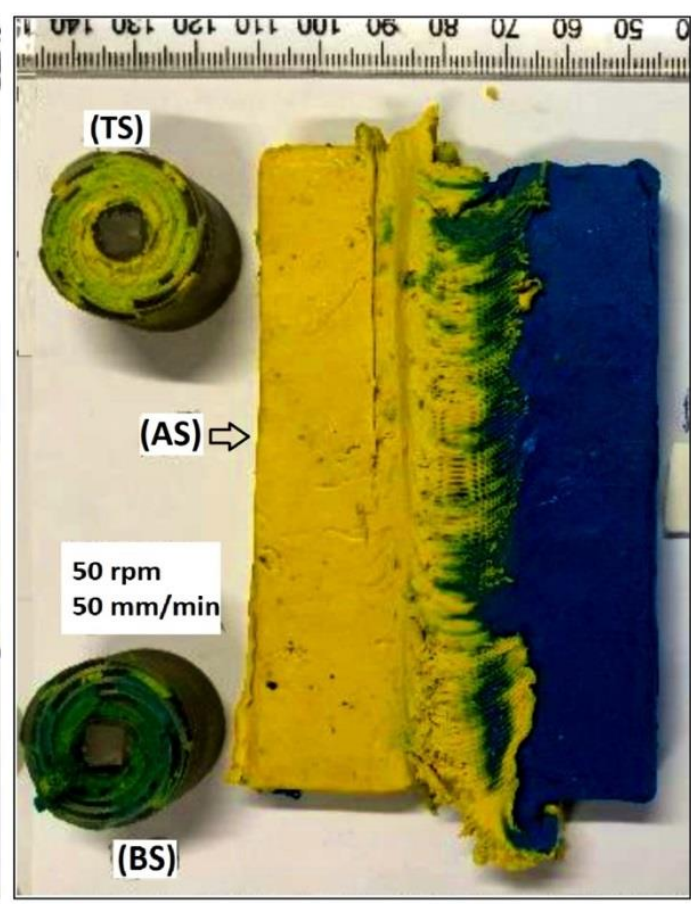

Multi Spiral

Fig. 8. Flow features from top surface (AS: advancing side, RS: retreating side, TS: top shoulder, BS: bottom shoulder)

The run with the double spiral shoulder had a smooth surface on both the advancing and retreating sides, while multi spiral shoulder caused extensive excavation of material from the advancing side and accumulation of transported material at the retreating side. The similar flow effects can be observed at the entry and exit zones as well. The profile tends to drag material from the advancing side to the retreating side over the entry area. For all the shoulder families, this intensifying effect of the mass flow were visualised by the increase of the number of shoulder profiles.

\section{Cross section}

The cross-section profile of the workpiece is shown in Figure 9. The pin was responsible for the material mixing in the middle region of the cross section. The arrows propose how the material was pulled inwards the centre of the pin and intermixed to fill the gap. However the inward plasticine flow was unable to converge, hence formation of the void. Another contributing factor is the thread on the pin moves the material upward.

\section{(1) Improvement of the cross sectional flow regime by increase in the number of cutting profiles}

The comparison of shoulders in the family of blade, spiral and circular was done based on the cutting profiles and their corresponding cross sections. The four-blade sample had a narrow tunnel defect where the plastic flow from the retreating section tried to fill the bottom with the granules of the mixed colour. 


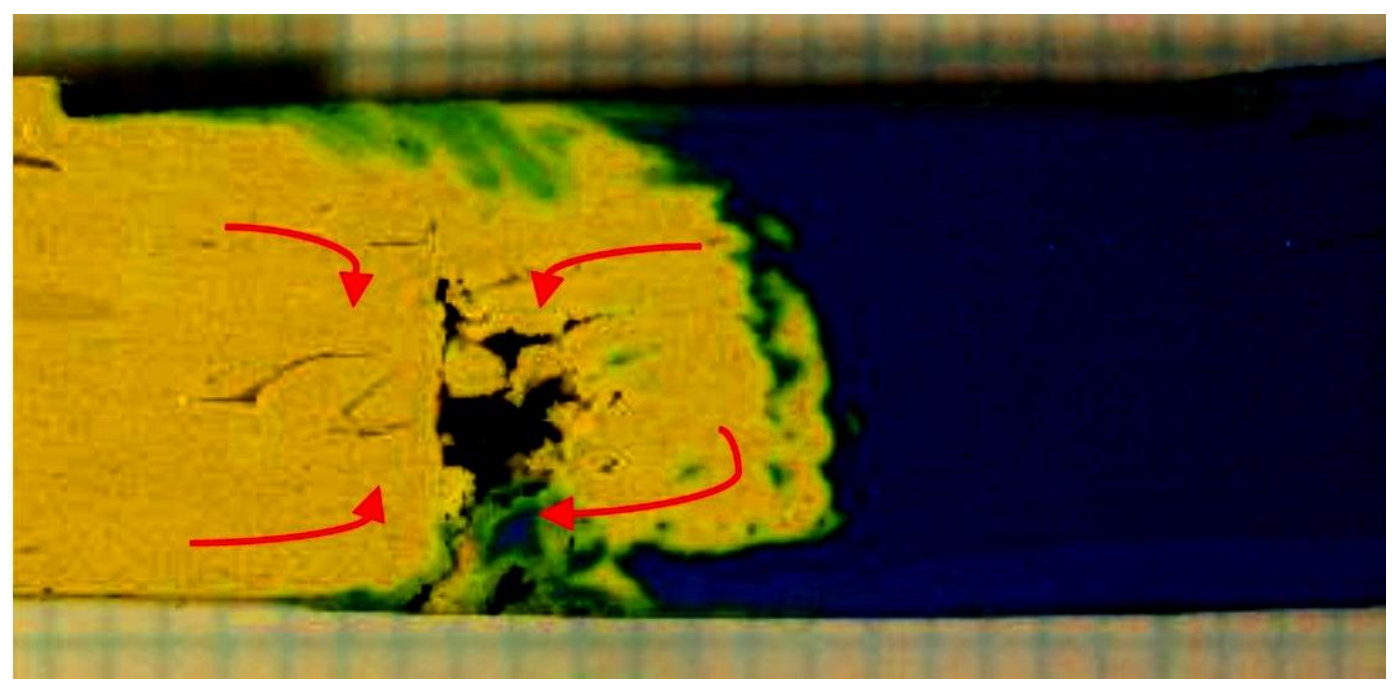

Fig. 9. Cross section of the plasticine analogue model of BFSW; flow patterns in the middle of the stirring zone in presence of the tunnel void defect

The tunnel zone in the three-blade sample had a wider defect and there existed a gap between the mass flows as shown in Figure 10. During analysis, it was observed that tunnel defect occurred on the bottom side of the advancing side. The weld bond was shown by the black circles corresponding to the bi-colour interface of the joint layer without any void between them. The rotation of the bottom shoulder accumulated some granules of retreating side material to fill the gap. In the Four blades sample, the material from the retreating section was pushed by rotation to move towards the advancing side and therefore the weld interface.

The common results in these tests were the shape and size of the tunnel defect from entry to exit. The void contained some mixed colour granules.

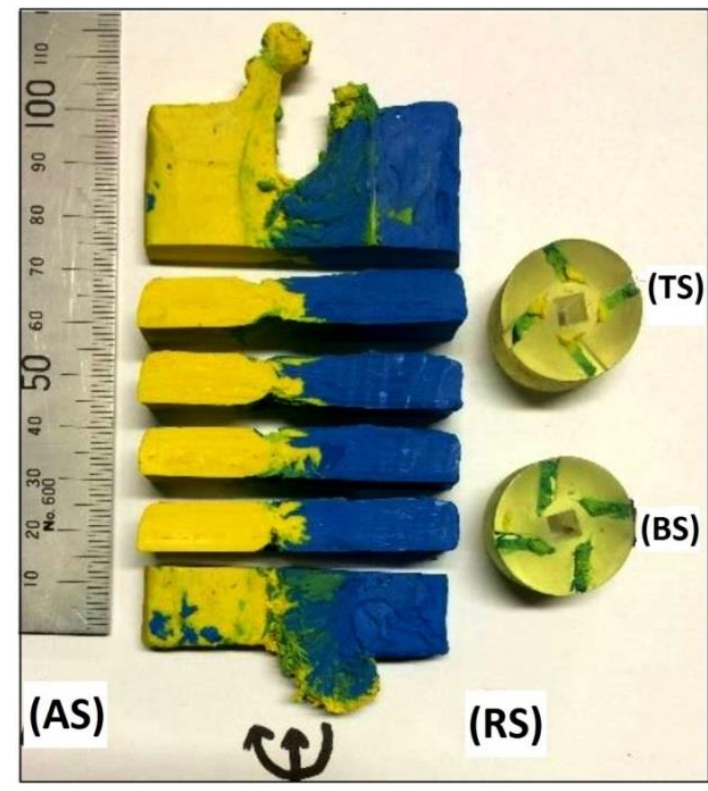

Four parallel blade

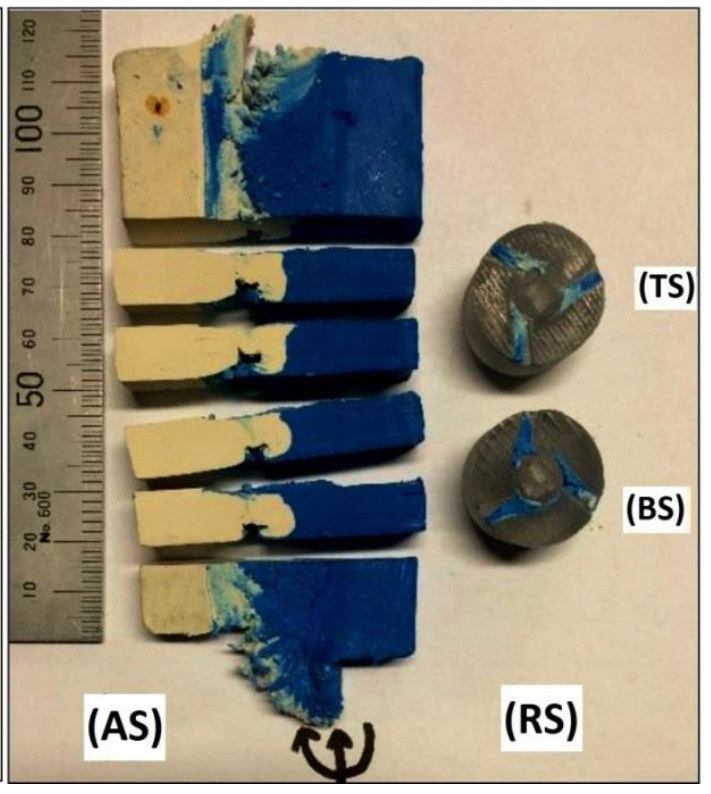

Three parallel blade

Fig. 10. Cross section of the plasticine analogue model of BFSW (AS: advancing side, RS: retreating side, TS: top shoulder, BS: bottom shoulder) 


\section{(2) Comparison of tunnel size and shape between shoulder families}

The comparison of the tunnel features is shown in the Figure 11 and Table 1. The symbols A, B and C represent the cross section near entry, centre and exit of the weld sample, respectively.

Table 1. Comparison of the cross section features

\begin{tabular}{cccc}
\hline Family & Shape & Depth & Width \\
\hline Blade & Irregular triangle & Shallow & Wide \\
Spiral & Irregular square & Shallow & Wide \\
Circular & Irregular square & Deep & Narrow \\
\hline
\end{tabular}

a. The blade family shoulders produced an irregular triangular-shape void but all the voids were filled by granules of the material. The depth of the tunnel was less than half the thickness. Width of the void was very large and in comparison to other families, it was largest. The top and bottom layers had plasticine excised due to the blade profiles.
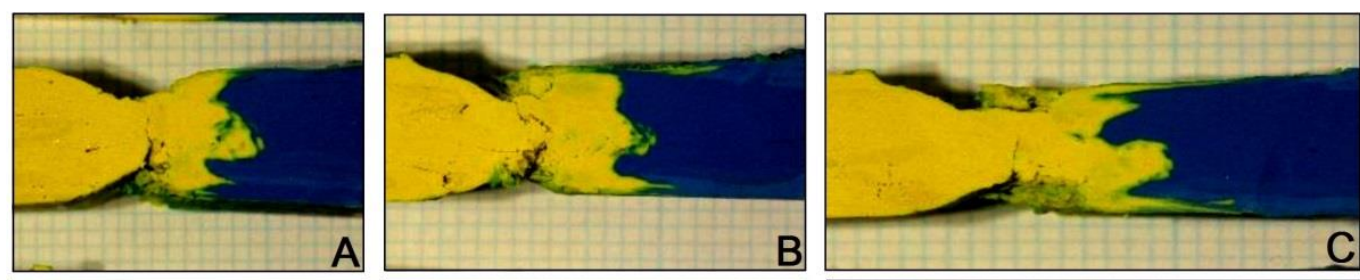

\section{BLADE}
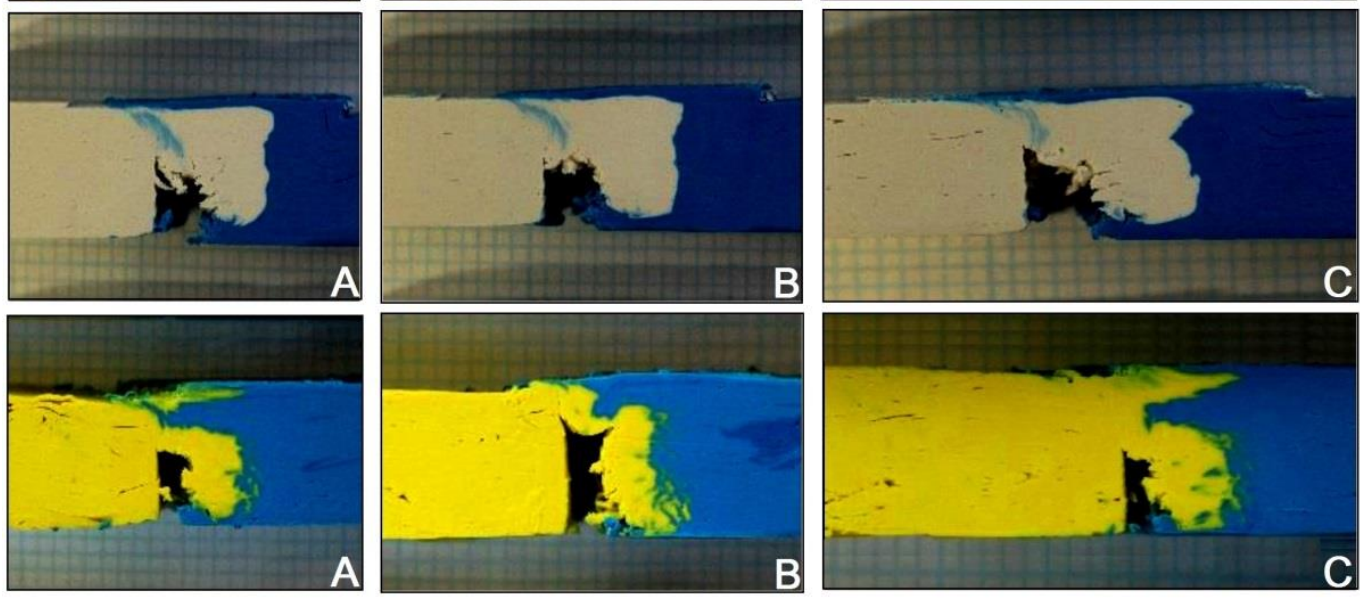

SPIRAL

Fig. 11. Cross section of the plasticine analogue model of BFSW samples

b. The spiral shoulders produced irregular square sections. The depth of the tunnel was almost half the thickness, but narrow. The top and bottom layer of the cross section was smooth due to less cutting of material. The tunnel void was almost empty with very few retreating granules filled at the bottom. The weld bond was nearly a straight path with most of advancing material.

c. The cross-section top and bottom layers were very smooth due to no material cutting from the edges. The tunnel void was irregular square, narrow but very deep. This deep void reduces the strength of the weld zone and this family of samples were supposed to be least safe from failure point of view. The weld bond was dominated by advancing side material, this did not allow retreating material to fill the bottom section of the weld zone. 


\section{Shoulders}

\section{- Material Flow}

The mix of material in the top and bottom shoulder recorded the evidence of material transportation on top and bottom surface. We can observe that the top shoulder had more material at the advancing side and a little mix of coloured material (see Figure 7). The bottom shoulder was filled by material more prominently from the retreating side. The prominent role of the shoulder-driven mass flow at the surface is shown in Figure 8. The top shoulder filled with a large amount of advancing material. The bottom shoulder had a mixture of mass flow, intermixing from both sides of the tool.

\section{- Mixed shoulder designs}

Some of the shoulder designs consisted of features from different families. The mixed shoulder having combined profiles of blade and circle is shown in Figure 12. These shoulders produced combined effects of the material flow. The blade features pushed the material from the advancing side towards the centre. The circular feature at the centre accumulated the material in form of a thick paste to refill the tunnel void position. The tunnel zone depth, shape and width were less than with other shoulder designs.
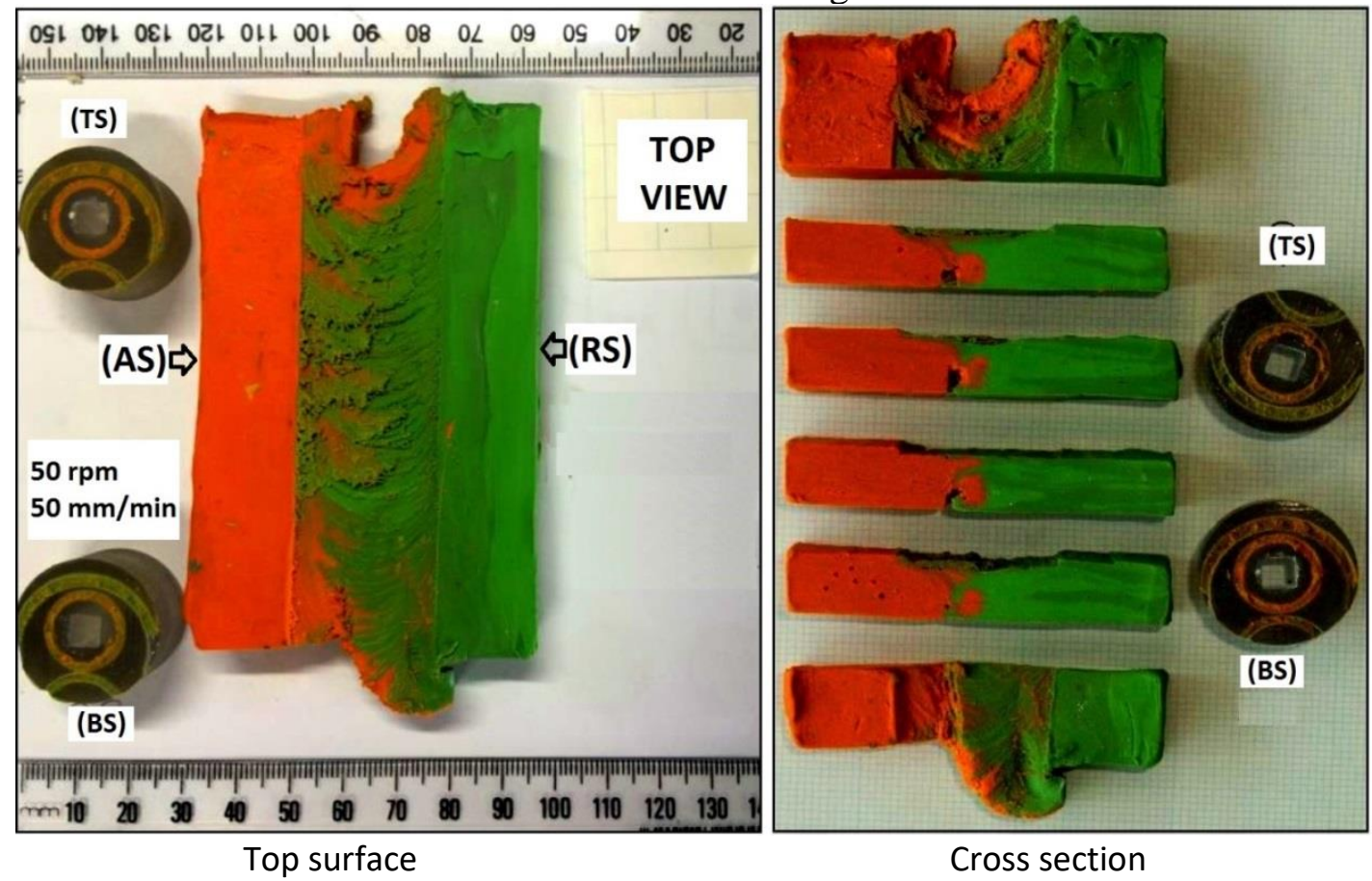

Fig. 12. Mixed shoulder test sample (AS: advancing side, RS: retreating side, TS: top shoulder, BS: bottom shoulder)

\section{DISCUSSION}

The main reason for the better surface quality under the top shoulder was due to the cutting edges, see Figure 7 . The wide cutting profiles tend to draw more material from the advancing side to retreating side. The top layer of material indicates more depth of the refilled layer from the top shoulder towards the bottom shoulder, see Figure 9. The movement of 
large lumps of the plastic mass from the advancing side to the retreating side also affects the quality of the cross section.

The impact of profile is identified. The cutting of large amount of advancing material was due to the material exposure at the edge of shoulders. In the double spiral, the cutting edge would proceed to the advancing side at an angle difference of $180^{\circ}$ degrees. Therefore, the advancing side and retreating side got enough spacing for intermixing of the mass flows to produce a smooth surface. The two-spiral shoulder during the rotating has more process time per profile. Moreover, the cut-out material from the advancing side was evenly distributed towards the retreating side and vice versa. Due to less time given to each profile under the same processing parameters, the profiles cut larger mass from the advancing side, aggregating it onto the retreating side.

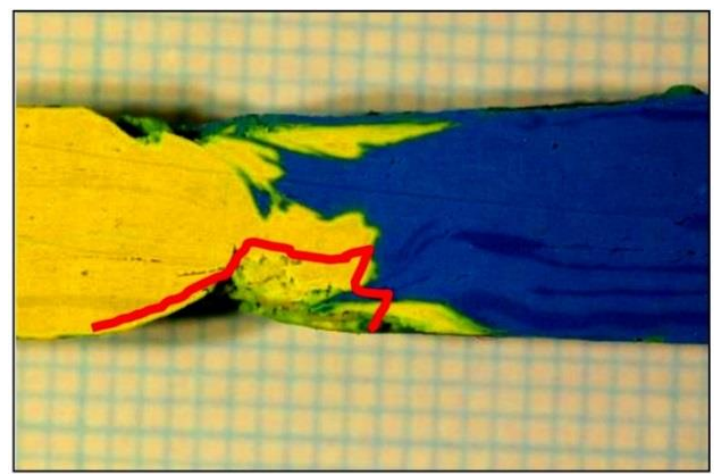

Four-parallel blade

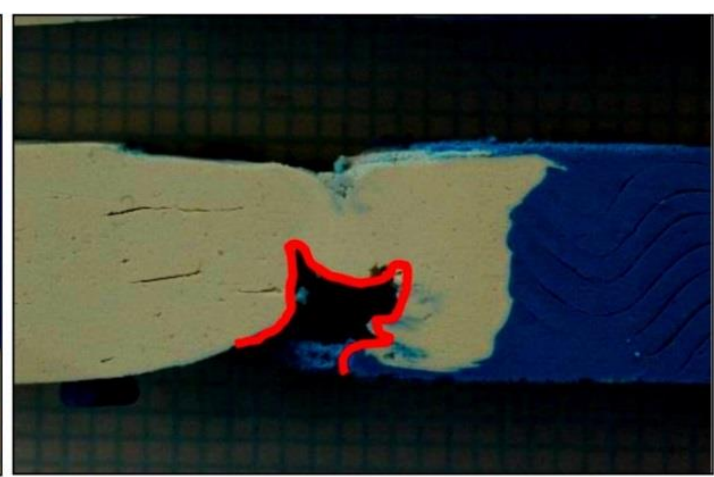

Three-parallel blade

Fig. 13. Material loss at the cross section

Figure 13 shows the cross section of the workpiece at similar locations for different number of shoulder profiles for the blade shape family. The red marked area was the tunnel defect. The threaded pin by rotation uplifts the material from the bottom of the advancing side [15], intermixes it with mass flow from retreating side, and deposits it to the retreating side. However, because of the shoulder restriction in mass transportation, there is a gap in the refilled mass there. The number of cutting profiles can influence the size and geometry of the tunnel void. The tunnel was not completely solid in four blades but granules of material, mixed from both colours, entered into the discontinuity gap. In case of three blades, the material from the retreating side was visible but very little was in the form of granules. The main reason was the material flow pattern towards the bottom of retreating side. The advancing side plasticine did not allow the retreating material to transport downwards, instead it restricted the flow.

The intermixed patterns at the sub-shoulder positions demonstrated the mixing of mass flows at the top and bottom surfaces. The results revealed the domination of flow driven by the top shoulders towards the advancing side and bottom shoulders to the retreating section. The material flow patterns confirm that the rotation of the tool can directly affect the mass transportation over the top and bottom surfaces. This was verified by running a test in opposite direction to the assumed default, which resulted in alteration of the surface features. The tunnel defect was emerged at the top surface area instead of bottom and the sub-shoulder mass flows interchanged to the space between the top and bottom shoulders. 
One of the better shoulder designs appeared to be a three blade structure, see Figure 14. In comparison to other shoulder samples, it had good surface and cross section features. The tunnel defect was minimised. The material in the shoulder grooves depicted good intermixing of the mass flows from both the advancing and retreating sides.
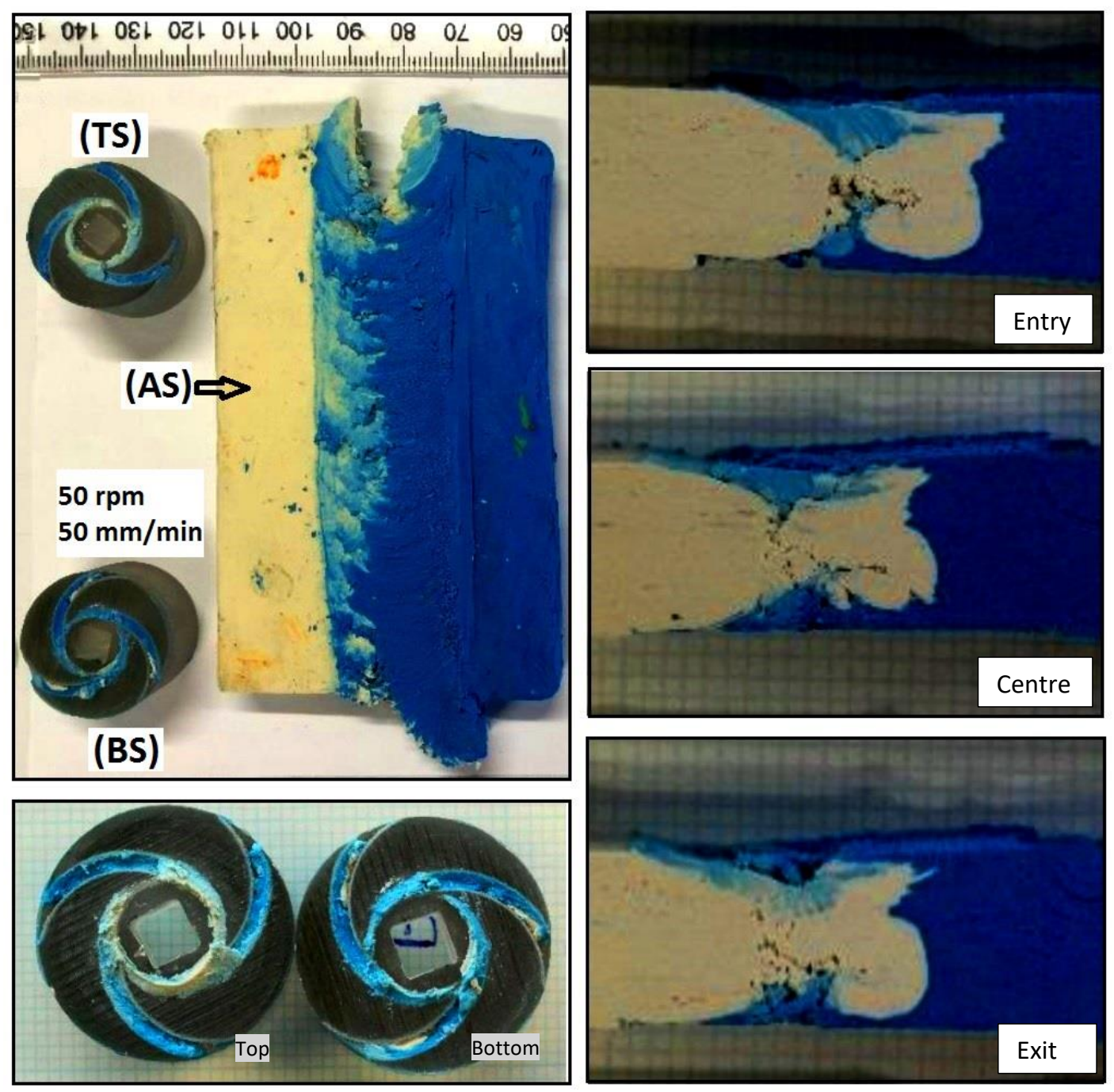

Fig. 14. Optimised shoulder design and the relevant material flow at the surface and cross-section, driven by the blade-scrolled shoulder performance (AS: advancing side, RS: retreating side, TS: top shoulder, BS: bottom shoulder)

\section{Material flow-phenomena in metallic joints}

To validate the flow visualization achieved by the plasticine, a real metal sample is needed for the comparison of the actual flow patterns. Figure 15 demonstrates the crosssection of the bimetal Aluminium-Copper joint, processed by the bobbin friction stir welding as per [17]. The dissimilar Al-Cu weld shows a better contrast of the material flow in the midSZ region of the weld, where the formation of the intermetallics and void defects are evident. The internal flow features show that the failure in mass transportation during the stirring action has a key role in formation of the void defect. Moreover, the dissimilar intermixing of 
mass flows at the mid-SZ region leads to the formation of the uncontrolled intermetallic compounds (IMCs). Both of these two physical defects are evident in the analogue model.

As discussed in Figures 11 and 13, the shearing flow effect driven by the shoulder action induces a severe plastic deformation from the surface towards the centre of the sample. Consequently, by the simultaneous pin action localized at the mid-SZ, the dissimilar joining bond layer forms at the interface of the Aluminium and Copper. It should be noted that the interruption in the refilling process disintegrates the deposition of the plastic layers transferred to the backing edge of the tool [31]. Therefore, the failure of the intermixing causes the flow discontinuity in the form of the void defect.

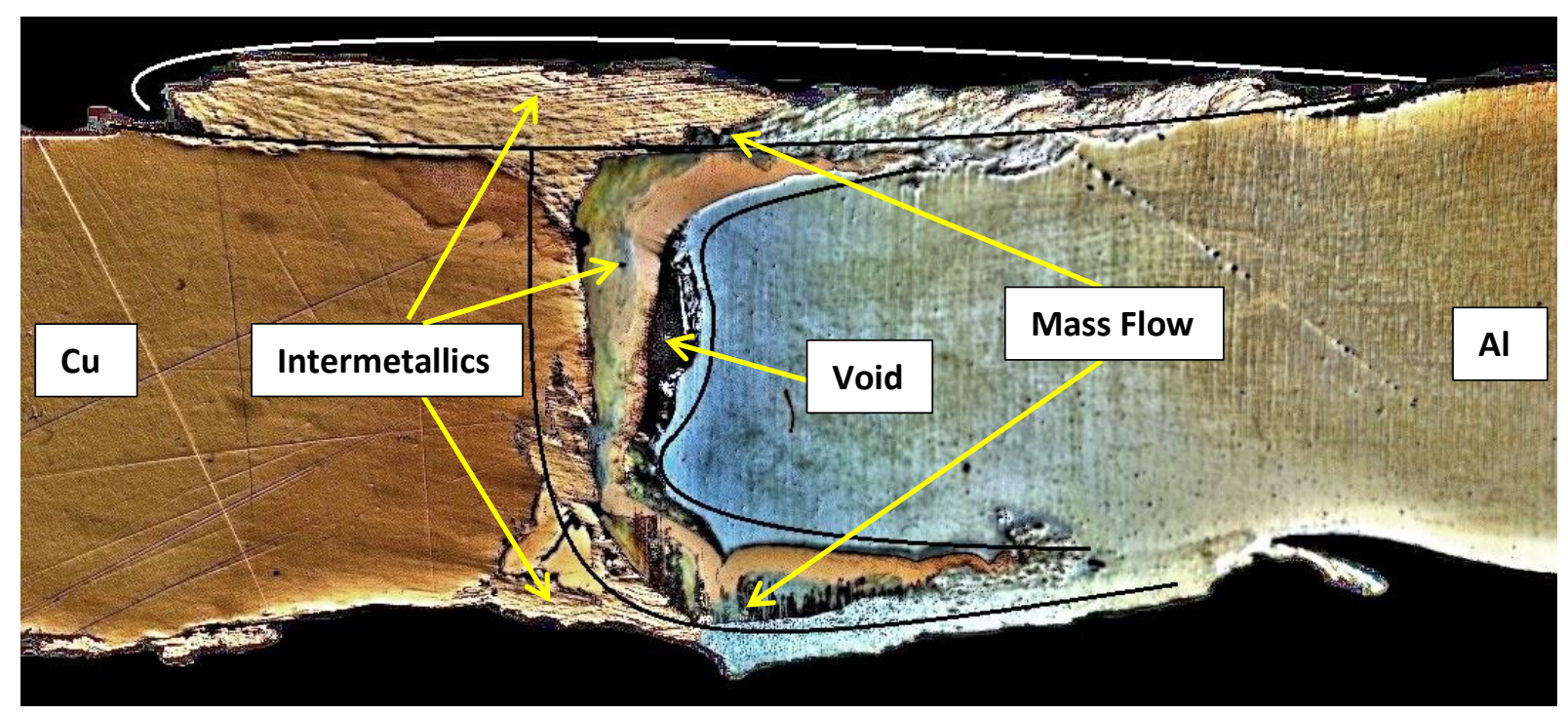

Fig. 15. Material flow in Aluminium-Copper bimetal joint, welded by BFSW technique

\section{Future Research}

The complete elimination of the tunnel defect was not possible by changes in the shoulder designs. Future research work can be done by changing the pin profile so that mixing and transportation of the plastic mass flow may result in complete termination of the tunnel defect.

\section{SUMMARY}

Based on the experimental results of the plasticine analogue model for the BFSW weld samples, it can be concluded that:

- An original flow visualization method was developed by an innovative analogue modelling of the BFSW process using plasticine samples instead of the actual metal welds.

- The flow patterns readily show the origins of the void defects arisen by the failure of the plastic deformation. 
- A dissimilar aluminium-copper joint successfully validated the flow regime. The similarity of the flow patterns in bi-colour plasticine samples and dissimilar $\mathrm{Al}-\mathrm{Cu}$ weld confirms the usefulness of the physical analogue model for flow visualization.

- The void discontinuity defect is attributed to the failure of the refilling process for the mass flow deposition in the stirring zone, and is related to the pin thread.

- The three-spiral shoulder features have greatest potential for producing good quality surface and refilled weld zone cross sections.

- The shape and width of the cutting edge shows the material flow transportation from advancing to retreating side under a severe plastic deformation induced by the stirring action.

- The circular profile shoulders showed smooth and evenly distributed surface flows.

\section{ORCID iD:}

Abbas Tamadon https://orcid.org/0000-0001-7367-4207

Dirk J. Pons https://orcid.org/0000-0001-7141-0291

Don Clucas https://orcid.org/0000-0002-6724-3037

\section{REFERENCES}

1. Thomas, W.; Nicholas, E.; Needham, J.; Murch, M.; Temple-Smith, P.; Dawes, C. Friction stir butt welding. International patent application no. PCT/GB92 Patent application 1991.

2. Murr, L.E.; Li, Y.; Trillo, E.A.; Flores, R.D.; McClure, J.C. Microstructures in friction-stir welded metals. Journal of Materials Processing and Manufacturing Science 1998, 7, 145-161.

3. Li, Y.; Murr, L.E.; McClure, J.C. Solid-state flow visualization in the friction-stir welding of 2024 Al to 6061 Al. Scripta Materialia 1999, 40, 1041-1046.

4. Benavides, S.; Li, Y.; Murr, L.; Brown, D.; McClure, J. Low-temperature friction-stir welding of 2024 aluminum. Scripta Materialia 1999, 41, 809-815.

5. Lambiase, F.; Derazkola, H.A.; Simchi, A. Friction Stir Welding and Friction Spot Stir Welding Processes of Polymers-State of the Art. Materials 2020, 13, 2291. https://doi.org/10.3390/ma13102291.

6. Carlone, P.; Palazzo, G. Characterization of TIG and FSW weldings in cast ZE41A magnesium alloy. Journal of Materials Processing Technology 2015, 215, 87-94.

7. He, Z.B.; Peng, Y.Y.; Yin, Z.M.; Lei, X.F. Comparison of FSW and TIG welded joints in Al-MgMn-Sc-Zr alloy plates. Transactions of Nonferrous Metals Society of China 2011, 21, 1685-1691.

8. Squillace, A.; De Fenzo, A.; Giorleo, G.; Bellucci, F. A comparison between FSW and TIG welding techniques: Modifications of microstructure and pitting corrosion resistance in AA 2024T3 butt joints. Journal of Materials Processing Technology 2004, 152, 97-105.

9. Tamadon, A.; Pons, D.J.; Clucas, D. AFM characterization of stir-induced micro-flow features within the AA6082-T6 BFSW welds. Technologies 2019, 7, 80.

10. Tamadon, A.; Baghestani, A.; Bajgholi, M.E. Influence of WC-based pin tool profile on microstructure and mechanical properties of AA1100 FSW welds. Technologies 2020, 8, 34.

11. Sued, M.K.; Pons, D.; Lavroff, J.; Wong, E.H. Design features for bobbin friction stir welding tools: Development of a conceptual model linking the underlying physics to the production process. Materials \& Design 2014, 54, 632-643. 
12. Colligan, K.J. Low-cost friction stir welding of aluminium for littoral combat ship applications. In 8th International Friction Stir Welding Symposium, TWI: Timmendorfer Strand, Germany, 2010.

13. Carstensen, J.; Dos Santos, J.F. Application of FSW and FSSW on advanced automotive structural applications. In 9th International Friction Stir Welding Symposium, Huntsville, USA, 2012.

14. Bordesoules, I.; Bigot, A.; Hantrais, C.; Odievre, T.; Laye, J. Aircracts structural parts demonstrators manufactured using friction stir welding. In 9th International Symposium on Friction Stir Welding, TWI: Huntsville, USA, 2012.

15. Grimm, A.; Schulze, S.; Silva, A.; Göbel, G.; Standfuss, J.; Brenner, B.; Beyer, E.; Füssel, U. Friction stir welding of light metals for industrial applications. Materials Today: Proceedings 2015, 2, S169-S178.

16. Tamadon, A.; Pons, D.; Sued, K.; Clucas, D. Formation mechanisms for entry and exit defects in bobbin friction stir welding. Metals 2018, 8, 33 .

17. Tamadon, A.; Abdali, M.; Pons, D.; Clucas, D. Characterization of dissimilar Al-Cu BFSW welds; interfacial microstructure, flow mechanism and intermetallics formation. Advances in Materials Science 2020, 20, 52-78.

18. Tamadon, A.; Pons, D.J.; Clucas, D.; Sued, K. Internal material flow layers in AA6082-T6 buttjoints during bobbin friction stir welding. Metals 2019, 9, 1059.

19. Tamadon, A.; Pons, D.J.; Clucas, D. Flow-based anatomy of bobbin friction-stirred weld; AA6082-T6 aluminium plate and analogue plasticine model. Applied Mechanics 2020, 1, 3-19.

20. Tamadon, A.; Pons, D.J.; Clucas, D. Structural anatomy of tunnel void defect in bobbin friction stir welding, elucidated by the analogue modelling. Applied System Innovation 2020, 3, 2.

21. Tamadon, A.; Pons, D.; Clucas, D. Analogue modelling of flow patterns in bobbin friction stir welding by the dark-field/bright-field illumination method. Advances in Materials Science 2020, 20, 56-70.

22. Tamadon, A.; Pons, D.; Sued, K.; Clucas, D. Thermomechanical grain refinement in AA6082-T6 thin plates under bobbin friction stir welding. Metals 2018, 8, 375.

23. Padmanaban, G.; Balasubramanian, V. Selection of FSW tool pin profile, shoulder diameter and material for joining AZ31B magnesium alloy-an experimental approach. Materials \& Design 2009, 30, 2647-2656.

24. Mohanty, H.; Mahapatra, M.; Kumar, P.; Biswas, P.; Mandal, N. Effect of tool shoulder and pin probe profiles on friction stirred aluminum welds - a comparative study. Journal of Marine Science and Application 2012, 11, 200-207.

25. Xu, S.-w.; Deng, X.; Reynolds, A.P.; Seidel, T. Finite element simulation of material flow in friction stir welding. Science and Technology of Welding and Joining 2001, 6, 191-193.

26. Seighalani, K.R.; Givi, M.B.; Nasiri, A.; Bahemmat, P. Investigations on the effects of the tool material, geometry, and tilt angle on friction stir welding of pure titanium. Journal of Materials Engineering and Performance 2010, 19, 955-962.

27. Sofuoglu, H.; Rasty, J. Flow behavior of plasticine used in physical modeling of metal forming processes. Tribology International 2000, 33, 523-529.

28. Wójcik, Ł.; Pater, Z. Physical analysis of cross-wedge rolling process of a stepped shaft. Advances in Science and Technology Research Journal 2017, 11.

29. Wójcik, Ł.; Pater, Z.; Bulzak, T.; Tomczak, J. Physical modeling of cross wedge rolling limitations. Materials 2020, 13, 867. 
30. Luo, J.; Wang, H.; Chen, W.; Li, L. Study on anti-wear property of 3D printed-tools in friction stir welding by numerical and physical experiments. The International Journal of Advanced Manufacturing Technology 2015, 77, 1781-1791.

31. Tamadon, A.; Pons, D.; Clucas, D. EBSD characterization of bobbin friction stir welding of AA6082-T6 aluminium alloy. Advances in Materials Science 2020, 20, 49-74. 